\title{
Color Change, Phenotypic Plasticity, and Camouflage
}

\author{
Martin Stevens * \\ Centre for Ecology and Conservation, College of Life and Environmental Sciences, University of Exeter, Penryn, UK
}

OPEN ACCESS

Edited by:

Wayne Iwan Lee Davies, University of Western Australia,

Australia

Reviewed by:

Chuan-Chin Chiao,

National Tsing Hua University, Taiwan Genevieve Anne Clare Phillips, The University of Queensland, Australia

${ }^{*}$ Correspondence:

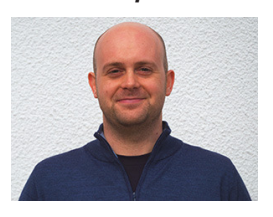

Martin Stevens

is Associate Professor of Sensory and Evolutionary Ecology at the University of Exeter. He did his PhD at Bristol

University on bird vision and animal camouflage, and then undertook several fellowships at Cambridge

University before moving to Exeter in

2013. His work has focussed on animal coloration, vision, and methods

to quantify visual signals, especially

image analyses. This has included work on camouflage, mimicry, brood parasites, and sexual signals. A major current area of work is to understand the adaptive value and mechanisms of color change and camouflage. martin.stevens@exeter.ac.uk

Received: 01 April 2016 Accepted: 25 April 2016 Published: 18 May 2016

Citation:

Stevens M (2016) Color Change,

Phenotypic Plasticity, and

Camouflage. Front. Ecol. Evol. 4:51.

doi: 10.3389/fevo.2016.00051
The ability to change appearance over a range of timescales is widespread in nature, existing in many invertebrate and vertebrate groups. This can include color change occurring in seconds, minutes, and hours, to longer term changes associated with phenotypic plasticity and development. A major function is for camouflage against predators because color change and plasticity enables animals to match their surroundings and potentially reduce the risk of predation. Recently, we published findings (Stevens et al., 2014a) showing how shore crabs can change their appearance and better match the background to predator vision in the short term. This, coupled with a number of past studies, emphasizes the potential that animals have to modify their appearance for camouflage. However, the majority of studies on camouflage and color plasticity have focused on a small number of species capable of unusually rapid changes. There are many broad questions that remain about the nature, mechanisms, evolution, and adaptive value of color change and plasticity for concealment. Here, I discuss past work and outline six questions relating to color change and plasticity, as well as major avenues for future work.

Keywords: camouflage, predation, color change, phenotypic plasticity, anti-predator

\section{INTRODUCTION}

One of the major challenges animals face is how to avoid being eaten by predators. Correspondingly, numerous species have evolved camouflage to avoid either detection or recognition (Stevens and Merilaita, 2009). A considerable problem, however, is how individuals can match the range of visual backgrounds against which they are often seen. Most camouflage types involve an interaction between the environment and an animal's phenotype, whereby appearance must, to a lesser or greater extent, resemble the background against which the animal is observed. Most habitats are not uniform, but rather exhibit considerable diversity in color, brightness, and pattern. One solution to this problem involves selection favoring the evolution of genetic polymorphisms in appearance, with individuals falling into one of a number of discrete morphs. Such polymorphisms, and their genetic basis, have been well studied in mice and reptiles (Nachman et al., 2003; Rosenblum et al., 2004; Rosenblum, 2006).

A problem with genetic polymorphism is that it lacks flexibility; an individual is still restricted to an appearance that would provide effective camouflage against a limited range of backgrounds, or in one habitat type. Camouflage cannot be modified to cope with changes in the environment with time, or with high heterogeneity in appearance among patches in space. Many of these problems can potentially be solved by the ability of individual animals to change appearance over time. This is widely documented in numerous species and taxa, ranging from crabs and caterpillars to mammals and reptiles (Stuart-Fox and Moussalli, 2009; Umbers et al., 2014). 


\section{KEY CONCEPT 1 | polymorphism}

Many species of crustacean that change color are also highly polymorphic, and this may allow valuable tests of camouflage mechanisms and function, and issues relating to intra-specific diversity.

Color change is not just used for camouflage. It commonly occurs in species for signaling functions, especially mate choice, ranging from color and brightness changes in chameleons (Ligon and McGraw, 2013) to polarization signals in mantis shrimp (Cronin et al., 2009). Another major function is likely to be in thermoregulation. Regarding camouflage, the majority of research has focused on relatively few species, and in particular those that are capable of extremely rapid changes (seconds), especially cephalopods (Hanlon et al., 2009; Chiao et al., 2011; Zylinski and Johnsen, 2011). While these studies have revealed much about how color change can be used to match different environments, and the visual feedback involved, color change of this speed is likely to be atypical in nature, especially outside of cephalopods and fish. Instead, the majority of animals likely change over periods of hours, days, weeks, and months (Umbers et al., 2014). This can involve modifications that occur through physiological color change, often thought to involve the contraction and dispersion of colored pigment within chromatophore cells, longer-term changes relating to morphology in cellular distribution and pigment synthesis, and in development (Stuart-Fox and Moussalli, 2009; Umbers et al., 2014). Most studies have largely focused on physiological processes, have not always considered functional and ecological issues, and numerous questions remain about the mechanisms and adaptive value of color change.

\section{KEY CONCEPT 2 | Color change}

Color change can operate over a range of timescales, from seconds and minutes to hours and days. Most work has focused on rapid color change but comparatively slow change is likely to be common in nature.

\section{KEY CONCEPT 3 | Costs and adaptive value of color change}

There are many unresolved questions in color change and camouflage, including how exactly color change works, what the metabolic costs are, and the adaptive advantage provided.

\section{USING CRABS TO STUDY COLOR CHANGE AND CAMOUFLAGE}

Perhaps the most widely used group of animals outside of cephalopods to study color change and its mechanisms has been crabs. Past work has focused particularly on fiddler crabs, Uca. Several species have a circadian day-night rhythm of color change (predominantly in terms of brightness), whereby individuals often become lighter at night and darker during the day (Atkins, 1926; Abramowitz, 1937; Brown and Webb, 1948). This can involve changes in the dispersion of black and white pigment in chromatophore cells (Abramowitz, 1937; Brown and Webb, 1948; Fingerman, 1955, 1956; Fingerman and Yamamoto, 1967; Rao et al., 1967), and is most likely to have a function in protecting the crabs from intense ultraviolet radiation (Darnell, 2012).
Some fiddler crabs also show higher levels of black and white pigment dispersion on dark and light backgrounds respectively (Brown and Sandeen, 1948; Rao et al., 1967), presumably for camouflage. Overall, despite considerable work on color change in Uca crabs, most has not been in the context of camouflage or focused on the ecological-evolutionary significance of color change. Furthermore, the majority of work, either over day-night and lunar cycles, or against different backgrounds, has involved assessments of color change using a pigment dispersion index of how spread out the pigment types appear to human eyes under a microscope. Comparatively few studies have quantified crab color change objectively (but see Hemmi et al., 2006; Detto et al., 2008; Darnell, 2012), and rarely their camouflage (Stevens et al., 2013, 2014a; Russell and Dierssen, 2015).

Recently, a study of color change in juvenile horned ghost crabs (Ocypode ceratophthalmus) assessed the color and brightness changes of individuals using measures of reflectance and color metrics derived from digital image analysis (Stevens et al., 2013). This showed that ghost crabs also have a circadian change in appearance, but unlike $U c a$, individual ghost crabs become darker and more gray at night, and lighter and more yellow during the day (Figure 1). These changes seemingly allow them to better match the color and brightness of the sandy beach during the day, and possibly to blend in with shadows at night. Furthermore, like $U c a$, the crabs become lighter when placed on a white background and darker when on a black background, potentially further refining their camouflage. Changes in brightness do not occur when crabs are simply placed in the dark. These experiments show how color change can potentially be used to modulate camouflage over a period of hours, although the study did not model the appearance or camouflage of the ghost crabs to predator vision. Other work has studied the coloration and camouflage of crabs found on Sargassum mats, which also seem to show marked changes in appearance depending on the substrate (Russell and Dierssen, 2015). This work modeled the appearance and camouflage of crabs to fish and avian vision, with crab camouflage better against the dichromatic fish system.

We recently conducted experiments to determine whether the common shore crab (Carcinus maenas) could change color over a period of $2 \mathrm{~h}$ to better match its background (Stevens et al., 2014a). Previous work by Powell (1962b) found that over a 90min period there were changes in the distribution of black and white pigment in chromatophore cells when crabs were placed on black or white backgrounds. In addition, shore crabs also show a circadian rhythm of change, becoming darker during the day and lighter at night (Powell, 1962a). However, this work did not analyze actual change in coloration per se, or individual match to the background. In our experiments, we tested juvenile crabs for changes in brightness on black or white backgrounds, and for changes in color on red or green backgrounds, and modeled the extent of color and luminance (perceived lightness) change of individuals to the visual system of an avian predator. We found that the crabs could change their brightness, becoming darker against the black background and lighter when on the white background (Figure 1). Although there was considerable individual variation and the changes were often not dramatic, 

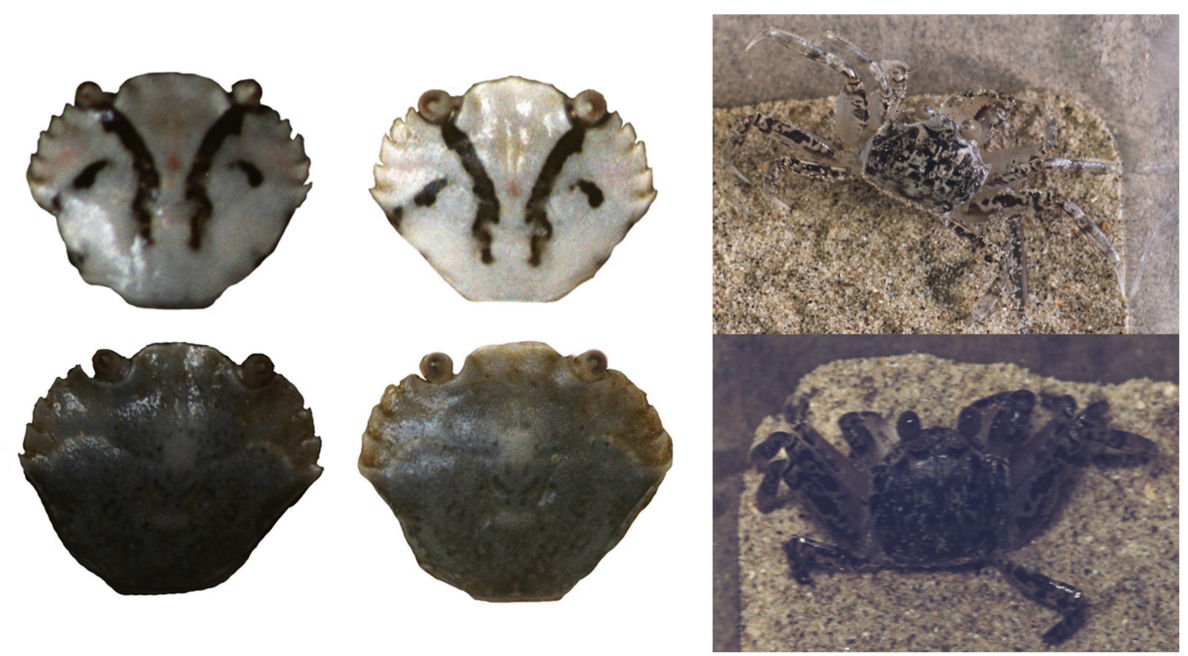

FIGURE 1 | Left image shows changes in the brightness of two shore crabs (Carcinus maenas) when placed on a black (left) and white (right) background for $\mathbf{2} \mathbf{h}$. From Stevens et al. (2014a). Right image shows a horned ghost crab during the day with light yellow coloration (top), and at night with dark gray coloration (bottom).

they were large enough in some individuals to lead to a better match to the background to a model of visual discrimination. Whether or not this would equate to a reduction in predation risk requires testing with predation/detection experiments. In contrast, we found no changes in color on the green and red backgrounds, at least to the extent that might alter camouflage.

Shore crabs, like a number of similar species, make an excellent system to study color change and plasticity and its role in concealment. First, there is increasing evidence that juveniles can undergo some changes in brightness that may improve camouflage (Powell, 1962b; Stevens et al., 2014a). In addition, they very likely undergo substantial changes in appearance through phenotypic plasticity as they molt (Todd et al., 2006; Stevens et al., 2014b; Jensen and Egnotovich, 2015; Figure 2). Indeed, signaling patterns in fiddler crabs can undergo substantial changes between molts (Detto et al., 2008). Second, shore crabs are a common and widely distributed species found in many habitats, potentially requiring different appearances to provide camouflage in each. Consistent with this, crabs from rocky, mudflat, and mussel bed type habitats show differences in both color and pattern (Todd et al., 2006, 2012; Stevens et al., 2014b; Figure 3). However, it is worth noting that despite a number of studies investigating phenotypeenvironment associations that are likely for camouflage (across a range of animal taxa), only one study of sand fleas has tested camouflage directly (e.g., phenotype-environment matching; Stevens et al., 2015). Third, shore crabs are highly variable in appearance even at the same location, seemingly with a wide range of camouflage tactics from background matching

\section{KEY CONCEPT 4 | Molting and plasticity}

Many crabs can change color both within the same molt and between molts. Like many other animals, this seemingly allows them to match the appearance of the background for concealment. to disruptive coloration (Hogarth, 1978; Stevens et al., 2014b; Figure 4). The level of diversity is linked to the habitat type/location where they live. This finding may allow tests of how high intraspecific diversity is produced and maintained. Fourth, their biology and robust nature makes them a perfect species to perform experiments and to determine the mechanisms of color change. Finally, outside of their native European range they are highly invasive across the world (one of the worlds "top 100" invasive species), meaning that they are a valuable system to study invasion biology (Darling et al., 2008; McGaw et al., 2011).

Despite progress in a number of areas regarding animal color change and camouflage, there remain a number of important outstanding questions relevant not just to crabs but across a range of animal taxa. Below, I outline six of the most important.

\section{WHICH ANIMALS CHANGE COLOR FOR CAMOUFLAGE AND WHAT DRIVES THE EVOLUTION OF COLOR CHANGE?}

Animals change color for several reasons, not just camouflage but also for thermoregulation, signaling, and protection from ultraviolet (UV) light. Few comparative analyses have been undertaken to fully explore the drivers of color change across widely distributed animal taxa, and these would be valuable in identifying the ecological factors involved (Stuart-Fox and Moussalli, 2009; Umbers et al., 2014). Certainly, color change for camouflage has been reported in numerous animal groups, including lepidopterans, crustaceans, cephalopods, reptiles, amphibians, fish, and more besides. In species of $U c a$, circadian changes may offer daytime protection from UV light at lower latitudes. However, protection from UV rays is less likely in more temperate shore crabs, especially given the northern distribution of their range. In contrast, thermoregulation (when in shallow 


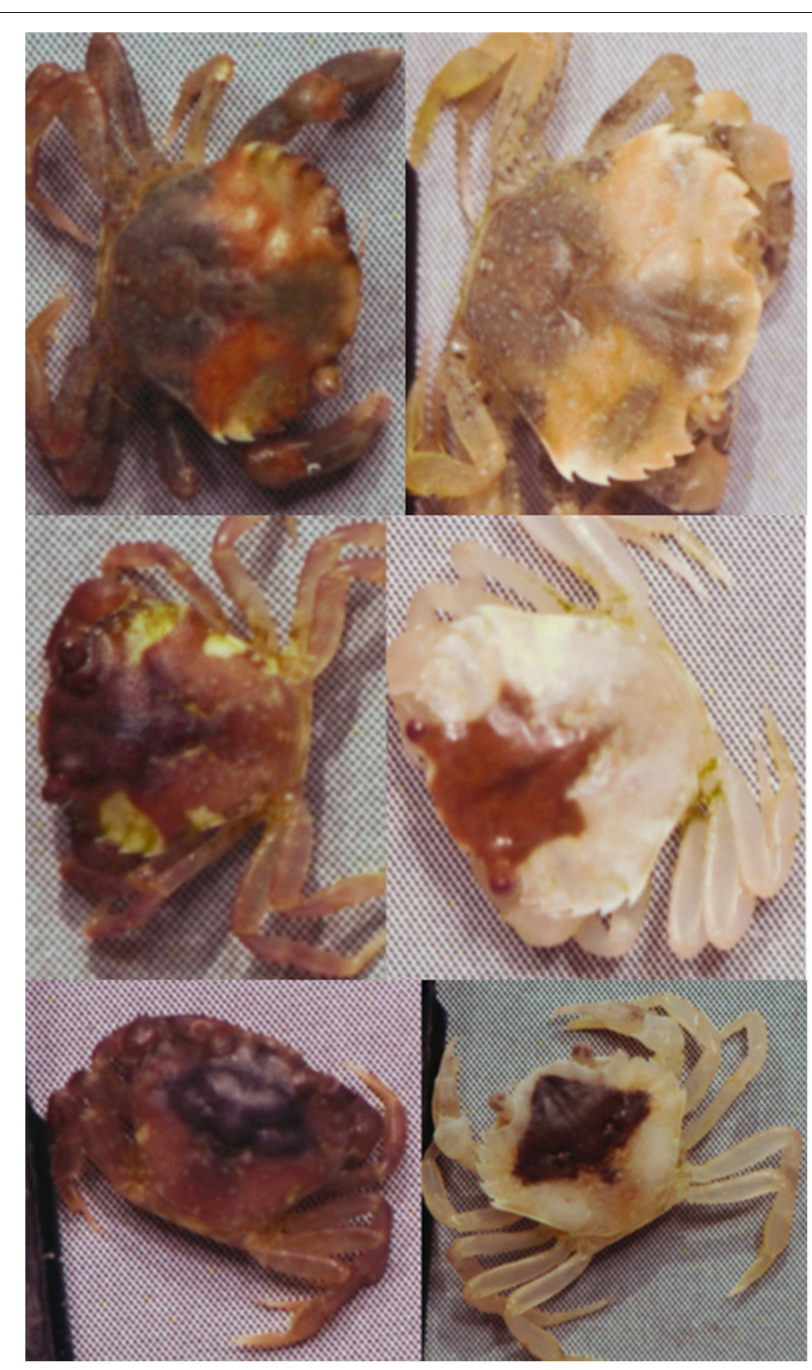

FIGURE 2 | Shore crabs (Carcinus maenas) kept on a heterogeneous light yellow sandy background can seemingly undergo considerable change in color and pattern as they molt (left = before molting, right = after).

water or exposed) during the day may be the reason. In ghost crabs, which become lighter during the day, the function seems to be for camouflage since the change improves the level of matching to the beach substrate. For all three species of crab, short-term changes in line with the background brightness would appear to be for concealment. Note, however, that few direct experimental tests of these proposed functions have been conducted (see below).

Another major underexplored area is how changes in appearance operate over varied timescales and the mechanisms involved, ranging from short term color change to longer term phenotypic plasticity (Nettle and Bateson, 2015). The majority of work on color change has been conducted on animals that change color rapidly (like cuttlefish and chameleons), or mostly focused on short-term modifications in species such as shore crabs. As discussed above, many of the most dramatic changes in appearance for many species likely involve molting (replacing the exoskeleton in invertebrates, and replacing fur or feathers in vertebrates). Such processes have rarely been tested or quantified but may have major implications for matching to environments and drivers of intraspecific diversity.

One of the advantages of phenotypic plasticity is that it can enable animals to change their appearance depending on the habitat where they live, or even to resemble specific background types/microhabitats (Keeble and Gamble, 1899; Gamble and Keeble, 1900; Rosenblum, 2006; Todd et al., 2006; Stevens et al., 2014b, 2015; Hultgren and Mittelstaedt, 2015; Jensen and Egnotovich, 2015; Russell and Dierssen, 2015; Duarte and Flores, 2016). This may be particularly valuable in species with high dispersal and planktonic larval stages, such as in many crustaceans, because there may be uncertainty as to where juveniles will settle and what the visual environment is like. Another feature of many of these species is that they have high levels of intraspecific diversity in color and pattern (Figures 4, 5) even at the same locality (Keeble and Gamble, 1899; Gamble and Keeble, 1900; Todd et al., 2006; Stevens et al., 2014b; CarvalhoBatista et al., 2015; Hultgren and Mittelstaedt, 2015; Jensen and Egnotovich, 2015; Duarte and Flores, 2016). The reasons for this are as yet largely unclear. In species like the shore crab it may allow matching to a range of different patch types in heterogeneous habitats, or prevent the formation of predator search images (Stevens et al., 2014b). They might also represent different types of camouflage strategies, such as background matching or disruptive coloration. A further largely unresolved question is why many crabs are highly variable in appearance among individuals as juveniles, but undergo ontogenetic changes as they grow (Figure 3). In many species, adults become less patterned and often darker, and apparently less cryptic (Palma and Steneck, 2001; Todd et al., 2006, 2009; Stevens et al., 2014b; Carvalho-Batista et al., 2015; Jensen and Egnotovich, 2015; Russell and Dierssen, 2015). Two possible explanations are that older/larger crabs move to different habitat types, requiring a different type of camouflage, or that as they grow bigger they become less susceptible to predation (Todd et al., 2009). In shore crabs, juveniles are likely highly vulnerable to both fish and avian predators, whereas the adults are more robust against attack from small to medium sized fish. Nonetheless, the function of this pattern of ontogenetic change is somewhat mysterious. It could help inform us about how camouflage works and interacts with body size, and trade-offs with other functions.

\section{HOW DOES COLOR CHANGE AND PLASTICITY WORK?}

With some notable exceptions (e.g., chameleons Teyssier et al., 2015), the ability of many animals to change color has mostly been studied in terms of changes in chromatophore cells containing different pigments (though other mechanisms occur in nature Umbers et al., 2014). Changes are often termed "physiological" when they involve changes in the state of chromatophore cells and dispersion of pigment over minutes and hours, and "morphological" when changes occur over days and 

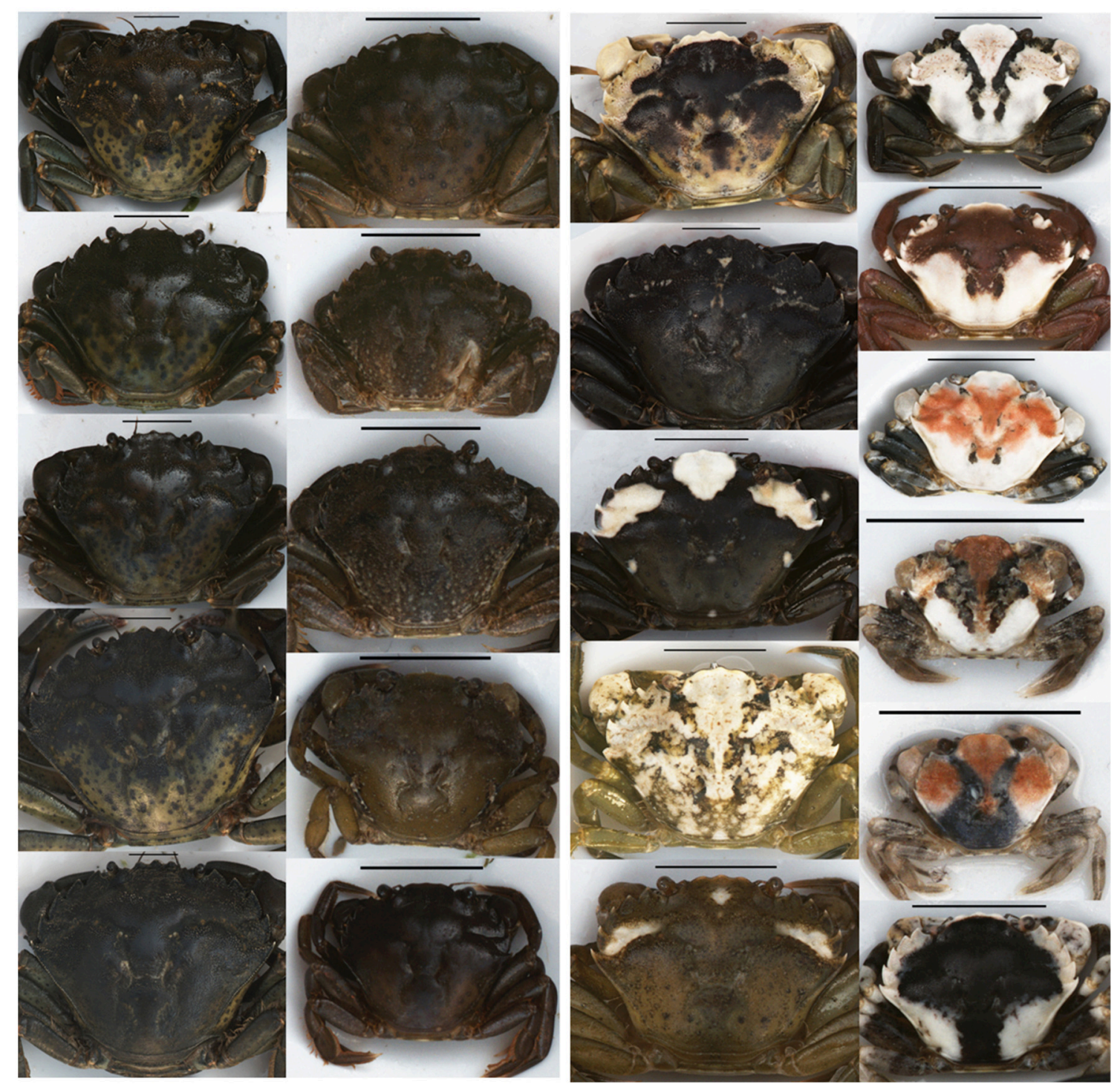

FIGURE 3 | Shore crabs (Carcinus maenas) differ depending on the habitat in which they live. Individuals from relatively uniform brown-green mudflats (left two columns) are more uniform and of similar color to the substrate, whereas those from colorful rock pool habitats (right two columns) are much more diverse and patterned. In each case, the column of crabs on the left hand side of the pairs are adults, which are often more uniform and less variable than juveniles. Images modified from Stevens et al. (2014b)

weeks due to synthesis and redistribution of pigment and cells over the body (Stuart-Fox and Moussalli, 2009). Again, much work has been undertaken in crabs on physiological changes.

In shore crabs, monocular microscope observations suggest that $C$. maenas has at least three types of chromatophore with red, white, and black pigment (Powell, 1962a). These have not been properly identified but are likely erythrophores (red carotenoid pigment), leucophores or iridophores (white-producing purines), and melanophores (black/brown melanin pigment). Shore crabs may also have xanthophores (yellow pteridine cells), which may allow them to become more yellow (Figure 2). Research on $U c a$ has identified similar chromatophore types. However, past work on most species has generally used subjective indices of chromatophore state or qualitative assessments over a short term (Fingerman and Yamamoto, 1967; Shibley, 1968; Jensen and Egnotovich, 2015), rather than detailed histology and pigment staining and identification over different time scales (especially ontogenetic changes), and has not coupled this to quantifying the changes in overall coloration produced. In addition, what happens during molting in crustaceans has not, to my knowledge been explored. Ideally, future work should couple modern advances in identifying pigment cells and types (e.g., Saenko et al., 2013) with quantification and visual modeling of changes in overall appearance. On top of this, the role of genetics and molecular pathways in color change potential and operation is as yet unknown. 


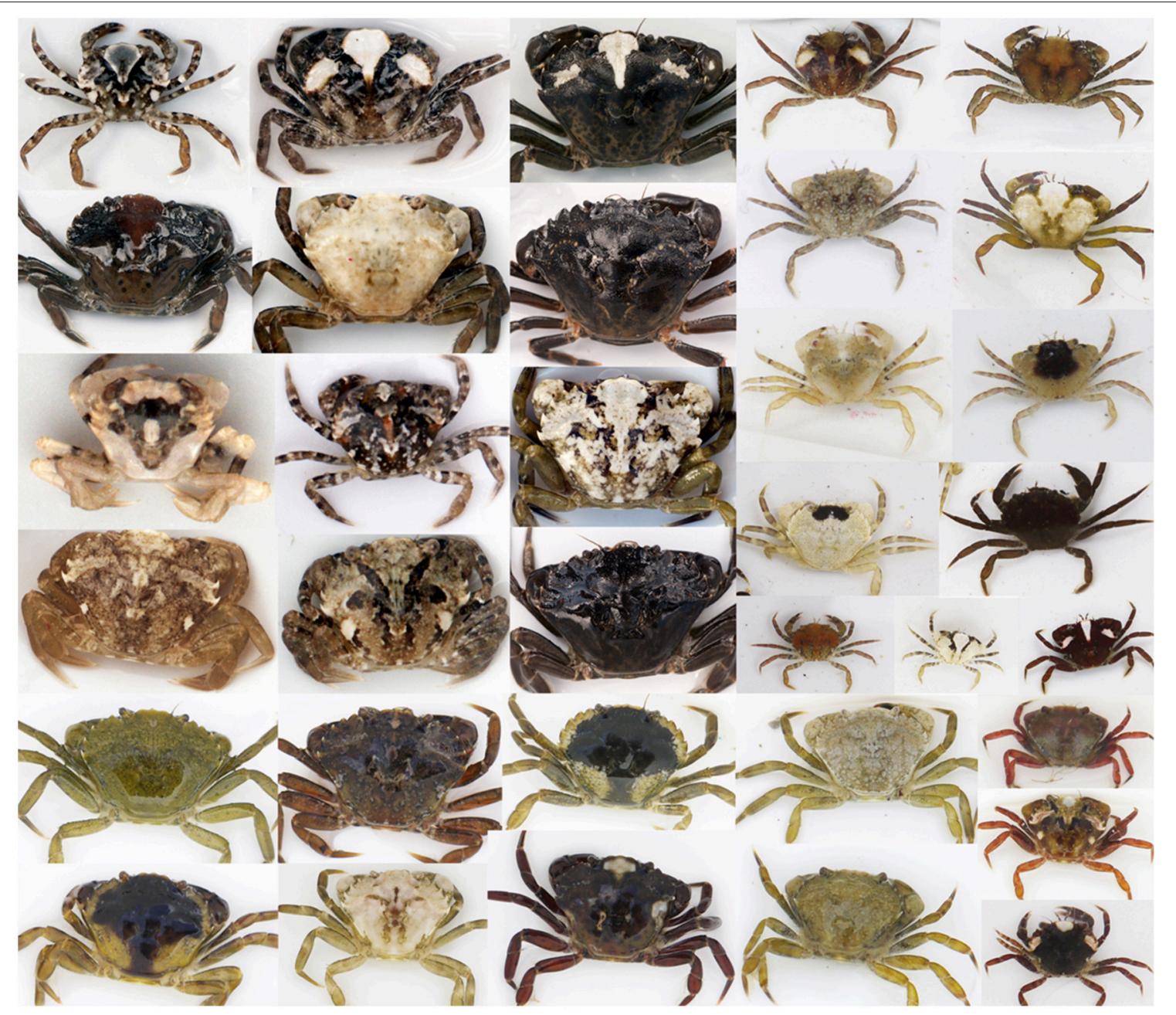

FIGURE 4 | The considerable variation in diversity that exists among shore crabs (Carcinus maenas). All these individuals (a mixture of adults and juveniles) are from just one rock pool site in Cornwall, UK.

It is also widely thought that, in addition to the direct action of light on chromatophore cells (primary response), color change is mediated based on visual information acquired by the animal concerning the environment where it lives (secondary response; Umbers et al., 2014). Specifically, it is often assumed that responses are mediated not by overall light levels, but by the ratio of incident light to the animal to reflected light from the substrate below, allowing individuals to match the brightness of the background independently of overall light levels (Keeble and Gamble, 1899; Gamble and Keeble, 1900; Sumner and Keys, 1929). This is consistent with work showing that, for example, ghost crabs do not simply become darker when placed in the dark (Stevens et al., 2013). Such information could be acquired by different patterns of light falling on different parts of the eye (Brown and Sandeen, 1948). Regarding color, animals may either have a color vision system capable of discriminating between different background colors, or, as seems the case in cuttlefish, they may be color blind and potentially use a rule of thumb about how different brightness and objects translate into a color, coupled with colored pigments that are a close match to the natural substrates (Mäthger et al., 2006, 2008). Alternatively, or in addition, cuttlefish may primarily match the brightness and pattern of the background if this is most important in facilitating camouflage. While these ideas seem logical and intuitive, very few experiments have tested these assumptions. Our work on shore crabs (Stevens et al., 2014a) showed no evidence for color change on red and green backgrounds. This may arise if crabs cannot tell the difference between these colors (or in the absence of brightness differences if crabs use achromatic mechanisms for matching colors). It seems likely that shore crabs can detect differences between relatively shortwave ("blue") and longwave ("red" or "yellow") light (Martin and Mote, 1982), but it is unclear whether they can discriminate between longwave and mediumwave light ("green," "red," and "yellow") too. However, longer term changes in color do occur (Figure 2), so it is more likely an issue that the timescale of our experiments was very short. 


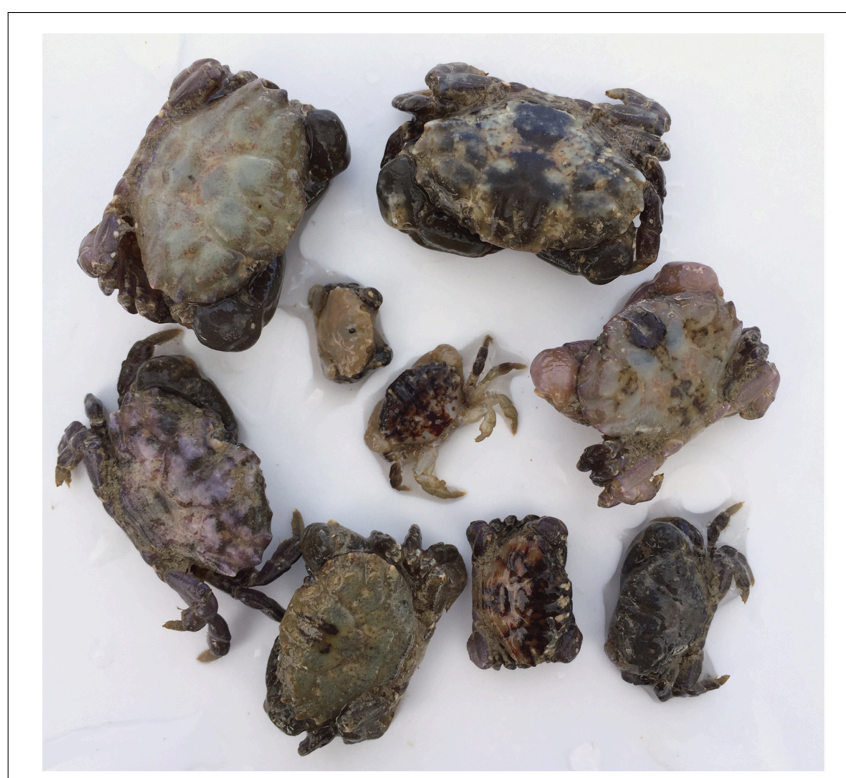

FIGURE 5 | Many crab species have extremely high levels of individual variation as juveniles, such as these furrowed crabs (Xantho incisus).

Further research has tested how dispersion of pigment in chromatophore cells might stem from visual information. In $U c a$ and other crustaceans, expansion state of chromatophore cells is at least partly based on hormones released from the eyestalks (e.g., Fingerman and Yamamoto, 1967; Fingerman, 1973). However, studies of Cancer crabs, removing either whole eyestalks, only the sinus gland complex (an eyestalk source of pigment dispersing hormones), or cutting optic nerves, suggests that visual information via the optic nerve is key to controlling pigment dispersion, not the presence of sinus glands alone (Shibley, 1968). That is, visual signals passing to the optic lobe seem crucial in controlling responses (presumably via other noneyestalk sources of hormone too). Therefore, work testing how visual information and the role of hormones link in crabs and other animals are needed to understand the pathways by which changes are controlled.

An additional recent consideration is that color change may be guided in some species by photoreceptors that are found outside of the eyes. For example, the skin of some cephalopods contain opsin proteins that are used in detecting light (Mäthger et al., 2010). Information from these proteins could be used to compliment color change guided by the eyes, and even enable parts of the body to tune their match to the adjacent environment. This may arise owing to comparisons with information from the chromatophore cells, which are also sensitive to light (Kingston et al., 2015; Ramirez and Oakley, 2015). Other recent work has shown that some geckos can change color to match the background when their eyes are covered, but not when their flanks were covered (which seemingly contain opsins; Fulgione et al., 2014). Further work on the role of extra-ocular light detection in guiding color change is needed.

Color change has also proven to be a valuable system to understand vision and perception. By manipulating the background in controlled ways, researchers have been able to determine what cues animals like cephalopods respond to and why, based on how they change patterns. This has shown that, among other things, cephalopods assess aspects of background intensity, encode the location of visual edges, perceive depth cues, and even undertake contour completion, filling in missing information from a visual scene (Kelman et al., 2007; Barbosa et al., 2008; Zylinski et al., 2009, 2012, 2016).

Finally, we should note that color change is not always solely influenced by visual information. In some prawns and caterpillars there is evidence from early and recent work that diet may have an important role, alone or in combination with vision, in influencing appearance changes (Keeble and Gamble, 1899; Gamble and Keeble, 1900; Greene, 1996; Noor et al., 2008).

\section{WHAT FUNCTION DO CIRCADIAN RHYTHMS OF COLOR CHANGE HAVE?}

It is common in a wide range of species for individuals to undergo changes from day to night. For example, aside from crabs, chameleon prawns (Hippolyte varians) change to a bluegray color, and animals from various other taxa undergo cycles too (Gamble and Keeble, 1900; Powell, 1962a; Darnell, 2012; Stevens et al., 2013). The functions of these cycles have, to my knowledge, rarely been tested. As discussed above, in ghost crabs it may facilitate camouflage, and in chameleon prawns it may enable better matching to the moonlight conditions. However, in all species it is often assumed, but apparently never tested, that changes in coloration at night may also be a mechanism of saving energy.

\section{WHAT COSTS ARE THERE TO COLOR CHANGE?}

Color change is widely thought to carry an energetic/metabolic cost, at least in terms of changing the state of chromatophore cells and synthesizing new pigment and cells, yet this has so far never been tested (Stuart-Fox and Moussalli, 2009). If the process of expanding or contracting chromatophore cells requires energy, then changes at night may be a mechanism to save costs, such as through the relaxation of muscles and modifications in cellular state, when visual predation and the need for camouflage is reduced. At night, pressure from visual predators is likely to be diminished (though this assumption requires testing), or crabs may also hide more under rocks and burrow into the substrate. Our work on both ghost crabs and shore crabs reveals considerable variation in the ability to change color/brightness (Stevens et al., 2013, 2014a). This may be linked to modification of color change rhythms associated with other factors such as tidal and lunar cycles, as is the case in some Uca species (Fingerman, 1956; Fingerman et al., 1958), but equally may reflect variation in the ability of some individuals to change color depending on their condition. Other costs and constraints are also likely to be involved with color change, including competing requirements of things like camouflage, thermoregulation, and UV protection. 


\section{WHAT IS THE ADAPTIVE VALUE OF COLOR CHANGE AND PLASTICITY?}

Perhaps the most obvious gap in our understanding of camouflage and color change is how this directly affects the risk of predation; that is, the adaptive value that color change for camouflage provides. Few if any studies have tested how color change influences predation behavior and detection by predators, or have done so indirectly (e.g., Hultgren and Mittelstaedt, 2015) and this should be a major aim for the future. In some regards, this lack of evidence is not surprising. Most recent work on camouflage efficacy has been conducted in artificial systems with human-made stimuli (e.g., Bond and Kamil, 2002; Cuthill et al., 2005; Merilaita and Lind, 2005; Webster et al., 2013), and even in the wild it is only recently that research has shown that the level of camouflage an animal has directly affects is likelihood of being attacked (Troscianko et al., 2016). Nonetheless, controlled experiments testing how color change affects predation risk are needed.

\section{WILL COLOR CHANGE ALLOW SOME ANIMALS TO COPE WITH THE EFFECTS OF A CHANGING WORLD?}

Logically, one might expect that the ability to change appearance might equip some species to cope with a changing world in the face of human disturbance. For example, if changes occur to the visual environment, color change may enable camouflage to remain effective. However, this would likely depend strongly on the mechanisms that guide changes. For example, in snowshoe hares, reduced snow cover and duration due to climate change is altering the background appearance but so far there is no evidence that hares can modify the timing of molting to transition from brown to white fur and back again in line with snow pack changes (Zimova et al., 2014). As a result, individuals will potentially become more mismatched to the environment, which in turn could disrupt their camouflage and thereby increase their likelihood of predation. However, these are seasonal changes, whereas alterations in appearance that occur on a smaller time frame may be more conducive to coping with human caused changes. Light pollution is also a major problem affecting much of the world, and can change the visual environment, especially if the spectrum of light at night deviates from that of moon

\section{REFERENCES}

Abramowitz, A. A. (1937). The chromatophorotropic hormone of the crustacea: standardization, properties and physiology of the eye-stalk glands. Biol. Bull. 72, 344-365. doi: 10.2307/1537694

Atkins, D. (1926). On nocturnal color change in the pea-crab (Pinnotheres veterum). Nature 117, 415-416. doi: 10.1038/117415b0

Barbosa, A., Mäthger, L. M., Buresch, K. C., Kelly, J., Chubb, C.-C., and Hanlon, R. T. (2008). Cuttlefish camouflage: the effects of substrate contrast and size in evoking uniform, mottle or disruptive body patterns. Vis. Res. 48, 1242-1253. doi: 10.1016/j.visres.2008.02.011 and sunlight (Gaston et al., 2013). An unanswered question is to what extent color change may enable animals to cope with this. Potentially, if the spectrum of artificial light is very different from daylight, then animals like crabs may change color at night under the unnaturally bright conditions to an appearance that mismatches the background under natural illumination during the day, meaning that color change at night actually diminishes diurnal camouflage. A further consideration is temperature and ocean acidity linked to climate change. In crabs there is evidence that color change can be affected by temperature (e.g., Powell, 1962b), and recent work has shown how behavioral and physiological responses of fish larvae can be affected by ocean acidification (Munday et al., 2009). How changes to the climate and oceans will affect the ability of animals to change color remains to be seen.

Color change and camouflage has proven to be a valuable system to study visual perception, physiology, and behavior. However, many key questions remain unanswered or untested, and the subject has the potential to reveal a great deal about evolution, intraspecific diversity, and adaptation to changing environments. Ultimately, the subject should continue to be a wonderful example of how research can combine a range of multi-disciplinary techniques, from cellular studies to vision modeling and behavioral experiments, and answer problems ranging from "top-down" evolutionary-ecological issues to "bottom-up" mechanistic questions (Kemp et al., 2015).

\section{AUTHOR CONTRIBUTIONS}

The author confirms being the sole contributor of this work and approved it for publication.

\section{FUNDING}

MS was funded by a Biotechnology and Biological Sciences Research Council David Phillips Research Fellowship (BB/G022887/1).

\section{ACKNOWLEDGMENTS}

I am very grateful to two referees and numerous colleagues for discussion and collaboration, including Peter Todd, Jenny Coomes, Jenny Easly, Ossi Nokelainen, Natasha Price, and Sara Mynott.

Bond, A. B., and Kamil, A. C. (2002). Visual predators select for crypticity and polymorphism in virtual prey. Nature 415, 609-613. doi: 10.1038/ 415609a

Brown, F. A., and Sandeen, M. I. (1948). Responses of the chromatophores of the fiddler crab, Uca, to light and temperature. Physiol. Zoo. 21, 361-371. doi: 10.1086/physzool.21.4.30152015

Brown, F. A., and Webb, H. M. (1948). Temperature relations of an endogenous daily rhythmicity in the fiddler crab, Uca. Physiol. Zoo. 21, 371-381. doi: 10.1086/physzool.21.4.30152016

Carvalho-Batista, A., Pescinelli, R. A., Garcia, J. R., Guerra, P. G. M., Pardo, L. M., and Mantelatto, F. L. (2015). Crypsis in the mud crab Panopeus 
americanus Saussure, 1857 (Decapoda, Panopeidae): relationship to sexual maturity. Crustaceanna 88, 963-977. doi: 10.1163/15685403-00003461

Chiao, C. C., Wickiser, J. K., Allen, J. J., Genter, B., and Hanlon, R. T. (2011). Hyperspectral imaging of cuttlefish camouflage indicates good color match in the eyes of fish predators. Proc. Natl. Acad. Sci. U.S.A. 108, 9148-9153. doi: 10.1073/pnas.1019090108

Cronin, T. W.-T.,Chiou, H., Caldwell, R. L. R. N., and Marshall, J. (2009). Polarization signals in mantis shrimps. Proc. SPIE 7461, 74610. doi: $10.1117 / 12.828492$

Cuthill, I. C., Stevens, M., Sheppard, J., Maddocks, T., Párraga, C. A., and Troscianko, T. S. (2005). Disruptive coloration and background pattern matching. Nature 434, 72-74. doi: 10.1038/nature03312

Darling, J. A., Bagley, M. J., Roman, J., Tepolt, C. K., and Geller, J. B. (2008). Genetic patterns across multiple introductions of the globally invasive crab genus Carcinus. Molec. Ecol. 17, 4992-5007. doi: 10.1111/j.1365-294X.2008.03978.x

Darnell, M. Z. (2012). Ecological physiology of the circadian pigmentation rhythm in the fiddler crab Uca panacea. J. Exp. Marine Biol. Ecol. 426-427, 39-47. doi: 10.1016/j.jembe.2012.05.014

Detto, T., Hemmi, J. M., and Backwell, P. R. Y. (2008). Colouration and color changes of the fiddler crab, Uca capricornis: a descriptive study. PLoS ONE 3:e1629. doi: 10.1371/journal.pone.0001629

Duarte, R. C., and Flores, A. A. V. (2016). Morph-specific habitat and sex distribution in the caridean shrimp Hippolyte obliquimanus. J. Marine Biol. Assoc. doi: 10.1017/s0025315416000230. [Epub ahead of print].

Fingerman, M. (1955). Persistent daily and tidal rhythms of color change in Callinectes sapidus. Biol. Bullet. 109, 255-264. doi: 10.2307/1538725

Fingerman, M. (1956). Difference in the tidal rhythms of color change of two species of fiddler crab. Biol. Bullet. 110, 274-290. doi: 10.2307/1538833

Fingerman, M. (1973). Behavior of chromatophores of the fiddler crab Uca pugilator and the dwarf crayfish Cambarellus shufeldti in response to synthetic Pandalus red pigment-concentrating hormone. Gen. Comp. Endocrin. 20, 589-592. doi: 10.1016/0016-6480(73)90093-2

Fingerman, M., Lowe, M. E., and Mobberly, W. C. (1958). Environmental factors involved in setting the phases of tidal rhythm of color change in the fiddler crabs Uca pugilator and Uca minax. Limnol. Oceanog. 3, 271-282. doi: 10.4319/lo.1958.3.3.0271

Fingerman, M., and Yamamoto, Y. (1967). Daily rhythm of melanophoric pigment migration in eyestalkless fiddler crabs, Uca pugilator (Bosc). Crustaceana 12, 303-319. doi: 10.1163/156854067X00279

Fulgione, D., Trapanese, M., Maselli, V., Rippa, D., Itri, F., Avallone, B., and Raia, P. (2014). Seeing through the skin: dermal light sensitivity provides cryptism in moorish gecko. J. Zool. 294, 122-128. doi: 10.1111/jzo.12159

Gamble, F. W., and Keeble, F. W. (1900). Hippolyte varians: a study in colorchange. J. Cell Sci. S2-43, 589-698.

Gaston, K. J., Bennie, J., Davies, T. W., and Hopkins, J. (2013). The ecological impacts of nighttime light pollution: a mechanistic appraisal. Biol. Rev. 88, 912-927. doi: 10.1111/brv.12036

Greene, E. (1996). Effect of light quality and larval diet on morph induction in the polymorphic caterpillar Nemoria arizonaria (Lepidoptera: Geometridae). Biol. J. Linn. Soc. 58, 277-285. doi: 10.1111/j.1095-8312.1996.tb01435.x

Hanlon, R. T.-C., Chiao, C., Mäthger, L. M., Barbosa, A., Buresch, K. C., and Chubb, C. (2009). Cephalopod dynamic camouflage: bridging the continuum between background matching and disruptive coloration. Phil. Trans. R. Soc. B 364, 429-437. doi: 10.1098/rstb.2008.0270

Hemmi, J. M., Marshall, J., Pix, W., Vorobyev, M., and Zeil, J. (2006). The variable colors of the fiddler crab Uca vomeris and their relation to background and predation. J. Exp. Biol. 209, 4140-4153. doi: 10.1242/jeb.02483

Hogarth, P. J. (1978). Variation in the carapace pattern of juvenile Carcinus maenas. Marine Biol. 44, 337-343. doi: 10.1007/BF00390898

Hultgren, K. M., and Mittelstaedt, H. (2015). Color change in a marine isopod is adaptive in reducing predation. Curr. Zool. 61, 739-748. doi: 10.1093/czoolo/61.4.739

Jensen, G. C., and Egnotovich, M. S. (2015). A whiter shade of male: color background matching as a function of size and sex in the yellow shore crab Hemigrapsus oregonensis (Dana, 1851). Curr. Zool. 61, 729-738. doi: 10.1093/czoolo/61.4.729

Keeble, F. W., and Gamble, F. W. (1899). The color-physiology of Hippolyte varians. Proc. R. Soc. B 65, 461-468. doi: 10.1098/rspl.1899.0059
Kelman, E., Baddeley, R., Shohet, A., and Osorio, D. (2007). Perception of visual texture, and the expression of disruptive camouflage by the cuttlefish, Sepia officinalis. Proc. R. Soc. B 274, 1369-1375. doi: 10.1098/rspb.2007.0240

Kemp, D. J., Herberstein, M. E., Fleishman, L. J., Endler, J. A., Bennett, A. T. D., and Whiting, M. J. (2015). An integrative framework for the appraisal of coloration in nature. Am. Nat. 185, 705-724. doi: 10.1086/681021

Kingston, A. C. N., Kuzirian, A. M., Hanlon, R. T., and Cronin, T. W. (2015). Visual phototransduction components in cephalopod chromatophores suggest dermal photoreception. J. Exp. Biol. 218, 1596-1602. doi: 10.1242/jeb. 117945

Ligon, R. A., and McGraw, K. J. (2013). Chameleons communicate with complex color changes during contests: different body regions convey different information. Biol. Lett. 9, 20130892. doi: 10.1098/rsbl.2013.0892

Martin, F. G., and Mote, M. I. (1982). Color receptors in marine crustaceans: a second spectral class of retinular cell in the compound eyes of Callinectes and Carcinus. J. Comp. Physiol. A 145, 549-554. doi: 10.1007/BF006 12820

Mäthger, L. M., Barbosa, A., Miner, S., and Hanlon, R. T. (2006). Color blindness and contrast perception in cuttlefish (Sepia officinalis) determined by a visual sensorimotor assay. Vis. Res. 46, 1746-1753. doi: 10.1016/j.visres.2005.09.035

Mäthger, L. M. -C., Chiao, C., Barbosa, A., and Hanlon, R. T. (2008). Color matching on natural substrates in cuttlefish, Sepia officinalis. J. Comp. Physiol. A 194, 577-585. doi: 10.1007/s00359-008-0332-4

Mäthger, L. M., Roberts, S. B., and Hanlon, R. T. (2010). Evidence for distributed light sensing in the skin of cuttlefish, Sepia officinalis. Biol. Lett. 6, 600-603. doi: $10.1098 /$ rsbl.2010.0223

McGaw, I. J., Edgell, T. C., and Kaiser, M. J. (2011). Population demographics of native and newly invasive populations of the green crab Carcinus maenas. Marine Ecol. Prog. Ser. 430, 235-240. doi: 10.3354/meps09037

Merilaita, S., and Lind, J. (2005). Background-matching and disruptive coloration, and the evolution of cryptic coloration. Proc. R. Soc. B 272, 665-670. doi: 10.1098/rspb.2004.3000

Munday, P. L., Dixson, D. L., Donelson, J. M., Jones, G. P., Pratchett, M. S., and Døving, K. B. (2009). Ocean acidification impairs olfactory discrimination and homing ability of a marine fish. Proc. Natl. Acad. Sci. U.S.A. 106, 1848-1852. doi: 10.1073/pnas.0809996106

Nachman, M. W., Hoekstra, H. E., and D’Agostino, S. L. (2003). The genetic basis of adaptive melanism in pocket mice. Proc. Natl. Acad. Sci. U.S.A. 100, 5268-5273. doi: 10.1073/pnas.0431157100

Nettle, D., and Bateson, M. (2015). Adaptive developmental plasticity: what is it, how can we recognize it and when can it evolve? Proc. R. Soc. B 282, 20151005. doi: 10.1098/rspb.2015.1005

Noor, M. A. F., Parnell, R. S., and Grant, B. S. (2008). A reversible color polyphenism in American peppered moth (Biston betularia cognataria) caterpillars. PLoS ONE 3:e3142. doi: 10.1371/journal.pone.0003142

Palma, A. T., and Steneck, R. S. (2001). Does variable coloration in juvenile marine crabs reduce risk of visual predation? Ecology 82, 2961-2967. doi: 10.1890/0012-9658(2001)082[2961:DVCIJM]2.0.CO;2

Powell, B. L. (1962a). Distribution and rhythmical behavior of the chromatophores of juvenile Carcinus maenas (L.). J. Anim. Ecol 31, 251-261. doi: 10.2307/2139

Powell, B. L. (1962b). The responses of the chromatophores of Carcinus maenas (L. 1758) to light and temperature. Crustaceana 4, 93-102. doi: $10.1163 / 156854062 X 00120$

Ramirez, M. D., and Oakley, T. H. (2015). Eye-independent, light-activated chromatophore expansion (LACE) and expression of phototransduction genes in the skin of Octopus bimaculoides. J. Exp. Biol. 218, 1513-1520. doi: 10.1242/jeb.110908

Rao, K. R., Fingerman, M., and Bartell, C. K. (1967). Physiology of the white chromatophores in the fiddler crab, Uca pugilator. Biol. Bullet. 133, 606-617. doi: $10.2307 / 1539922$

Rosenblum, E. B. (2006). Convergent evolution and divergent selection: lizards at the White Sands ecotone. Am. Nat. 167, 1-15. doi: 10.1086/498397

Rosenblum, E. B., Hoekstra, H. E., and Nachman, M. W. (2004). Adaptive reptile color variation and the evolution of the MC1R gene. Evolution 58, 1794-1808. doi: 10.1554/03-741

Russell, B. J., and Dierssen, H. M. (2015). Use of hyperspectral imagery to assess cryptic color matching in Sargassum associated crabs. PLoS ONE 10:e136260. doi: 10.1371/journal.pone. 0136260 
Saenko, S. V., Teyssier, J. D., van der Marel, and Milinkovitch, M. C. (2013). Precise colocalization of interacting structural and pigmentary elements generates extensive color pattern variation in Phelsuma lizards. BMC Biol. 11:105. doi: 10.1186/1741-7007-11-105

Shibley, G. A. (1968). Eyestalk function in chromatophore control in a crab, Cancer magister. Physiol. Zool. 41, 268-279. doi: 10.1086/physzool.41.3.30155460

Stevens, M., Broderick, A. C., Godley, B. J., Lown, A. E., Troscianko, J., and Weber, S. B. (2015). Phenotype-environment matching in sand fleas. Biol. Lett. 11, 20150494. doi: 10.1098/rsbl.2015.0494

Stevens, M., Lown, A. E., and Wood, L. E. (2014a). Color change and camouflage in juvenile shore crabs Carcinus maenas. Front. Ecol. Evol. 2:14. doi: 10.3389/fevo.2014.00014

Stevens, M., and Merilaita, S. (2009). Introduction. Animal camouflage: current issues and new perspectives. Phil. Trans. R. Soc. B 364, 423-427. doi: 10.1098/rstb.2008.0217

Stevens, M., Pei Rong, C., and Todd, P. A. (2013). Color change and camouflage in the horned ghost crab Ocypode ceratophthalmus. Biol. J. Linn. Soc. 109, 257-270. doi: $10.1111 /$ bij.12039

Stevens, M., Wood, L. E., and Lown, A. E. (2014b). Camouflage and individual variation in shore crabs (Carcinus maenas) from different habitats. PLoS ONE 9:e115586. doi: 10.1371/journal.pone.0115586

Stuart-Fox, D., and Moussalli, A. (2009). Camouflage, communication and thermoregulation: lessons from color changing organisms. Philos. Trans. R. Soc. B 364, 463-470. doi: 10.1098/rstb.2008.0254

Sumner, F. B., and Keys, A. B. (1929). The effects of differences in the apparent source of illumination upon the shade assumed by a flatfish on a given background. Physiol. Zool. 2, 495-504. doi: 10.1086/physzool.2.4.30152972

Teyssier, J., Saenko, S. V., van der Marel, D., and Milinkovitch, M. C. (2015). Photonic crystals cause active color change in chameleons. Nat. Comm. 6, 6368. doi: $10.1038 /$ ncomms 7368

Todd, P. A., Briers, R. A., Ladle, R. J., and Middleton, F. (2006). Phenotypeenvironment matching in the shore crab (Carcinus maenas). Marine Biol. 148, 1357-1367. doi: 10.1007/s00227-005-0159-2

Todd, P. A., Oh, J., Loke, L. H. L., and Ladle, R. J. (2012). Multi-scale phenotypesubstrate matching: evidence from shore crabs (Carcinus maenas L.). Ecol. Complex. 12, 58-62. doi: 10.1016/j.ecocom.2012.09.005

Todd, P. A., Qiu, W., and Chong, K. Y. (2009). Ontogenetic shifts in carapace patterning and/or colouration in intertidal and subtidal brachyuran crabs. Raffles Bullet Zool. 57, 543-550.
Troscianko, J., Wilson-Aggarwal, J., Stevens, M., and Spottiswoode, C. N. (2016) Camouflage predicts survival in ground-nesting birds. Sci. Rep. 6, 19966. doi: 10.1038/srep19966

Umbers, K. D. L., Fabricant, S. A., Gawryszewski, F. M., Seago, A. E., and Herberstein, M. E. (2014). Reversible color change in Arthropoda. Biol. Rev. 89, 820-848. doi: 10.1111/brv.12079

Webster, R. J., Hassall, C., Herdman, C. M., and Sherratt, T. N. (2013). Disruptive camouflage impairs object recognition. Biol. Lett. 9, 20130501. doi: 10.1098/rsbl.2013.0501

Zimova, M., Mills, L. S., Lukacs, P. M., and Mitchell, M. S. (2014). Snowshoe hares display limited phenotypic plasticity to mismatch in seasonal camouflage. Proc. R. Soc. B 281, 20140029. doi: 10.1098/rspb.20 14.0029

Zylinski, S.-A., Darmaillacq, S., and Shashar, N. (2012). Visual interpolation for contour completion by the European cuttlefish (Sepia officinalis) and its use in dynamic camouflage. Proc. R. Soc. B 279, 2386-2390. doi: 10.1098/rspb.2012.0026

Zylinski, S., and Johnsen, S. (2011). Mesopelagic cephalopods switch between transparency and pigmentation to optimize camouflage in the deep. Curr. Biol. 21, 1937-1941. doi: 10.1016/j.cub.2011. 10.014

Zylinski, S., Osorio, D., and Johnsen, S. (2016). Cuttlefish see shape from shading, fine-tuning coloration in response to pictorial depth cues and directional illumination. Proc. R. Soc. B 283, 20160062. doi: 10.1098/rspb.20 16.0062

Zylinski, S., Osorio, D., and Shohet, A. (2009). Perception of edges and visual texture in the camouflage of the common cuttlefish, Sepia officinalis. Phil. Trans R. Soc. B 364, 439-448. doi: 10.1098/rstb.2008.0264

Conflict of Interest Statement: The author declares that the research was conducted in the absence of any commercial or financial relationships that could be construed as a potential conflict of interest.

Copyright (C) 2016 Stevens. This is an open-access article distributed under the terms of the Creative Commons Attribution License (CC BY). The use, distribution or reproduction in other forums is permitted, provided the original author (s) or licensor are credited and that the original publication in this journal is cited, in accordance with accepted academic practice. No use, distribution or reproduction is permitted which does not comply with these terms. 